\title{
Liquidity of Non-financial Corporations: Evidence from Bulgaria
}

Received: 17.05 .2021

Available online: 29.09.2021

\section{Yanko Hristozov*}

\section{Abstract}

The financial and economic crisis years ago put the development of enterprises in Bulgaria and around the world in an uncontrollable environment that is difficult to predict, and led to significant problems with their financial condition. As a result of a rare CoVid-19 pandemic in 2020, the economic situation has become more complicated and portends déjà vu in terms of negative effects on the economy and businesses. The numerous closures of businesses and entire sectors will undoubtedly lead to serious financial consequences related to liquidity problems and excessive indebtedness of Bulgarian enterprises. The main problem that provokes this study is the lack of summarized information on the state of corporate liquidity and the solvency levels of non-financial corporations in Bulgaria. The main purpose of the article is to examine the liquidity status of non-financial corporations in Bulgaria. This analysis is needed to prevent liquidity crises and to bring out early indicators to warn and counter the risks posed by deteriorating solvency. It will be essential for the liquidity assessment to derive average industry values of the indicators to guide the companies from the sectors regarding the recommended liquidity levels to which they should strive.

Keywords: Corporate Liquidity, Solvency JEL: F65, G31

\section{Introduction} ver the last years the enterprises in
Bulgaria have experienced a range of transformations, from a change in political and economic governance in some difficult early years of transition to stabilization and an accelerated economic growth (Nenkova, P., Popova, N., Metalova, D., 2021).

For this reason, issues related to the financial condition and provision of liquidity and working capital in the company are always on the agenda and are the basis of its financial stability and independence. Often liquidity, this important financial indicator for the company is neglected, not managed and controlled qualitatively, which leads to problems with solvency and sometimes with excessive debt. In the following lines, an attempt will be made to analyze and assess the liquidity status of Bulgarian non-financial corporations. For this purpose, the methodology of the research will be determined, a literature review of significant research to date on the topic will be made and indicators will be derived to guide companies in the event of liquidity risks.

\footnotetext{
Department of Finance, UNWE
} 


\section{Articles}

\section{Methods and Methodology}

The main aim of the research is to study the state of liquidity and indebtedness of non-financial sector enterprises in Bulgaria, to derive early warning indicators for solvency problems and to highlight some key approaches to liquidity management. It is essential to derive industry-wide values of liquidity ratios to serve as a guide for maintaining the necessary levels of liquidity in the respective sectors. To achieve this goal, the following research tasks are set:

- To study the specialized literature on the subject.

- To obtain the necessary statistical information to be processed, systematized and fed with correct data for analysis.

- To choose appropriate tools and methodology for liquidity research.

- To measure the indicators for structural, functional liquidity and the financial cycle of the non-financial enterprises from the sectors according to the classifier for the economic activities of the NSI based on the annual consolidated reports.

- To derive industry averages of different financial indicators.

- To propose indicators for early warning, related to liquidity problems of the companies.

The object of study are the non-financial enterprises (NSI, KID-2008) from the following economic sectors according to the KID-2008: Sector A, B, C, D, E, F, G, H, I, J, L, M, N, $S$. A restriction is set in terms of the period: 2008 - 2018, which is necessary due to the lack of more up-to-date data by the NSI at the time of preparing the analysis. The subject of research is the analysis of the liquidity situation of non-financial corporations in Bulgaria.
Liquidity of Non-financial Corporations: Evidence from Bulgaria

In connection with the realization of the set research aim and tasks, the following working hypothesis can be formulated: it is possible to measure industry averages for relative liquidity ratios to serve as a guide for companies in different sectors. On this basis, to propose early warning indicators to assist management in dealing with risks of insolvency, liquidity problems and excessive indebtedness.

The methods that will be used for the implementation of the research project include research of specialized literature sources, documentary analysis, comparative analysis, expert evaluation, empirical research method, analysis and synthesis, induction and deduction, modeling, mathematical methods. Two methods will be used to measure liquidity structural (short-term) liquidity and cash conversation cycle.

\section{Literature Review}

According to Panigrahi (2008), the goal of working capital management should be to enable a firm to maximize the profits of its operations while meeting both short-term debt and upcoming operational expenses, i.e., to preserve liquidity. But increasing profitability would tend to reduce the firms' liquidity and too much attention on liquidity would tend to affect the profitability. Every firm tries to maximize the profitability by preserving the liquidity. According to E. Raykov (2017), the primary objective of financial managers is commonly defined through their role in maximizing the wealth of shareholders in the long term.

Businesses pursue different goals. Two of them are dominant and these are on the one hand maintaining stable financial levels of liquidity, and on the other hand acquiring the goals of achieving the required return (Stahl, 


\section{Articles}

Weber-H., 2018). Liquidity measurement is an integral part of financial statement analysis, especially in credit assessments, and liquidity ratios are often used in empirical research in financial accounting (Emery, G., Cogger, K., 1982). Interest in this topic has been growing recently as changes or possible changes in financial reporting requirements.

The liquidity and corporate finance literature provides abundant evidence that liquidity is beneficial in many corporate settings: liquidity increases the power of governance via exit, reduces the cost of governance via intervention, facilitates the entrance of informed traders who produce valuable information about the firm, enhances the effectiveness of equity-based compensation to managers, reduces the cost of equity financing, mitigates trading frictions investors encounter when trading in the market to recreate a preferred payout policy, and lowers the immediate transaction costs and subsequent liquidity costs for firms conducting large share repurchases (Holden, Craig W., Jacobsen, Stacey E. and Subrahmanyam, A, 2014).

Financial ratios can make it easier for investors to understand information on financial statements (Widyastuti, M., 2019). Asset liquidity (or asset availability) affects companies' operational and financial decisions (Shleifer A., Vishny, R., 1992, Schlingemann, F, Stulz, R., Walkling, R., 2002 and Ortiz-Molina H., Phillips, G., 2014). For companies in a difficult financial situation, the degree of liquidity of assets is crucial, as they can sell assets to avoid bankruptcy. As mentioned by Hotchkiss and Mooradian (1998); Maksimovic and Phillips (1998), some companies are successfully acquired by other companies as a form of exit strategy, but others fail. The basic financial purpose of a corporation is the creation of its value. Liquidity management should also contribute to the realization of this fundamental aim. Many of the current asset management models that are found in financial management literature assume book profit maximization as the basic financial purpose (Michalski, G. 2008). The development of interest rates and volumes are well captured by the employed variables and their statistically significant signs coincide with the theoretical literature and are closely connected to corporate liquidity (Chobanov, P., Nenovsky, N., 2004).

An enterprise is generally recognized as insolvent when it is unable to meet its outstanding obligations in full and on time. There are two versions of insolvency: cash flow insolvency and balance sheet insolvency. Cash flow insolvency occurs when an organization is unable to meet its shortterm obligations due to liquidity constraints. Bankruptcy of the balance sheet occurs when the total liabilities of the company exceed its total assets; the organization is 'insolvent', even if it can service its debts in the near term (Homonnof, T., Spreen Th., Clair, T., 2020).

Treuz Erichsen (2016) notes that liquidity refers to the ability of an enterprise to meet all payment obligations on time and at any time. The goal of net companies should always be to have slightly more liquid funds at their disposal than repayment obligations. But it is essential to look for the optimal level of liquidity, because over liquidity is also a problem. Both cases can lead to financial problems and a crisis.

Working capital management is related to current assets, where the expected economic benefit is one-time or within one year ( $\mathrm{N}$. Nikolova, 2010). In this regard, controlling cash and liquidity levels is particularly important during and after crises, as lack 


\section{Articles}

of cash and liquidity is still one of the main causes of bankruptcy (Heesen, B, 2016). Economic crises are characterized by a sharp decline in consumption and demand, deteriorating liquidity in enterprises, increasing intercompany indebtedness and increasingly difficult access to financial resources. Crises in enterprises are an objective phenomenon inherent in any developing system.

They occur at different intervals, with different scales and forms of manifestation and can recur. As a rule, crises interact, affect each other. Crises in more complex systems and areas, when they develop simultaneously, acquire a synergistic effect, deepen, but also lead to a complex renewal of interconnected systems. The crisis of the individual enterprise may not coincide with any of the more comprehensive economic crises, it may be due to the development cycle of the enterprise, subjective errors or others. The liquidity crisis is a situation in which the undertaking is unable to repay its short-term liabilities on time. Often a corporate liquidity crisis leads to a debt crisis, the relationship is clearly defined along the line of ensuring solvency.

For this reason, the worst consequence of the liquidity crisis is insolvency. In this case, the company is not able to meet its undisputed obligations to contractors, creditors, budget within the established time limits. This is a difficult test of the managerial skills of any management. In this regard, the typology of crises and their interrelationship and conditionality are considered. The liquidity crisis does not appear suddenly, but always appears at a certain time, most often after wrong strategic decisions, limited views on the future and pressure exerted by the time to react to management.

According to G. Breitkreuz (2007), the most common causes of liquidity crises
Liquidity of Non-financial Corporations: Evidence from Bulgaria

are related to the following main situations and factors: first, incorrect or untimely response to market and market changes, poor information security. The dynamic development of the market, the competition can reduce the vigilance of the enterprise, and the lack of up-to-date information can affect adequate management decisions. Other reasons are insufficient acceptance of responsibility and obligations for planning, monitoring, coordination and control activities, inadequate accounting, lack of reporting or poor reporting, lack of budgeting in the company and monthly analysis of the reasons for deviations between forecast and actual results, poor investments due to the lack of strategic planning and underestimation of the market, large investments in fixed assets with a source of working capital. Secondly, cash and mismanagement, which contribute to poor liquidity - insufficient use of borrowed capital bank loans, such from suppliers or customers, leasing, factoring, etc., cash outflow by paying dividends, without the presence of the necessary working capital for the turnover in the enterprise, a significant increase in costs at the expense of turnover, the lack of or insufficient profitability, shrinking equity, debit indebtedness.

Liquidity problems affect investment activity. Pham, Ly Thi Minh, Vo, Lai Van, Le, Huong Thi Thu and Le, Danh Vinh, (2018) ask the question whether the liquidity of the company's assets matters for investment costs. In an ideal world, asset liquidity should not matter, as companies can finance their investments without incurring transaction costs. However, market imperfections affect the firms' ability to raise capital, thus potentially influencing investment policies. The competitiveness of the company is also a key element of the causes of the liquidity crisis 


\section{Articles}

and the decline leads to failure in demand from buyers, non-fulfillment of sales and deliveries, ignorance or poor management of working capital, dissatisfaction and retreat by longtime customers.

In their research "The Role of Liquidity in Financial Crises" Allen Frankling and Elena Carletti (2008) consider the liquidity crisis effects on the real economy. They focus on some of the crucial features of the crisis that are related to liquidity provision. In the opinion of the authors the first is the fall of the prices of AAA-rated tranches of securitized products below fundamental values. The second is the effect of the crisis on the interbank markets for term funding and on collateralized money markets. The third is the fear of contagion should a major institution fail.

Using Form 990 data reported by public charities, Adrian, Tobias and Shin, Hyun Song, (2009) documented significant bunching of nonprofits at near-zero net assets, the threshold for insolvency. Bunching occurs even though creditors cannot force insolvent nonprofits into involuntary bankruptcy. The authors show that the extent of bunching is greater among organizations that rely more heavily on contribution revenue, and that by inflating their net assets, bunching organizations can increase their contribution revenue relative to firms that report negative net assets.

\section{Analysis of corporate Liquidity in Bulgaria (2008-2018).}

Liquidity is an important issue in making financial decisions. It includes investments in assets that require appropriate financing. However, liquidity problems are usually overlooked by companies in making financial decisions, as this involves investment and financing in the short term. If a company does not have enough liquidity to pay its bills and suppliers, the situation could quickly deteriorate. Due to the presence of market friction, there are usually significant variations in liquidity ratios between different types of firms depending on the size of the industry and the degree of financial leverage (Dang, $H ., 2020)$. This statement supports the thesis and will be illustrated in the next few points.

\subsection{Structural Liquidity (Hristozov, 2021)}

Structural liquidity uses the wellknown ratios for measuring the solvency of enterprises and it shows its financial condition in the short term. The most known ratios are (Nenkov, D., Hristozov, Y., 2020):

\section{- Current Ratio $=\frac{\text { current assets }}{\text { short-term liabilities }}$}

\section{- Quick Ratio =}

current assets-inventory-prepaid expenses short-term liabilities

\section{- Cash Ratio $=\frac{\text { cash and cash equivalents }}{\text { short-term liabilities }}$}

The purpose of the following graphs is to summarize the results obtained for current, quick and cash liquidity by sector. In this way, the sectoral conditionality will be clearly illustrated and the significant difference between the individual sectors and the enterprises that are part of them will be highlighted. The dashed line of the following four graphs represents the average of the respective coefficient based on all sectors by specific years. To measure the average liquidity, relative to the specific ratio, the total amounts of the types of current assets and short-term liabilities are used. Figure 1 shows the current liquidity ratio, which represents the ratio between current assets and shortterm indebtedness. 


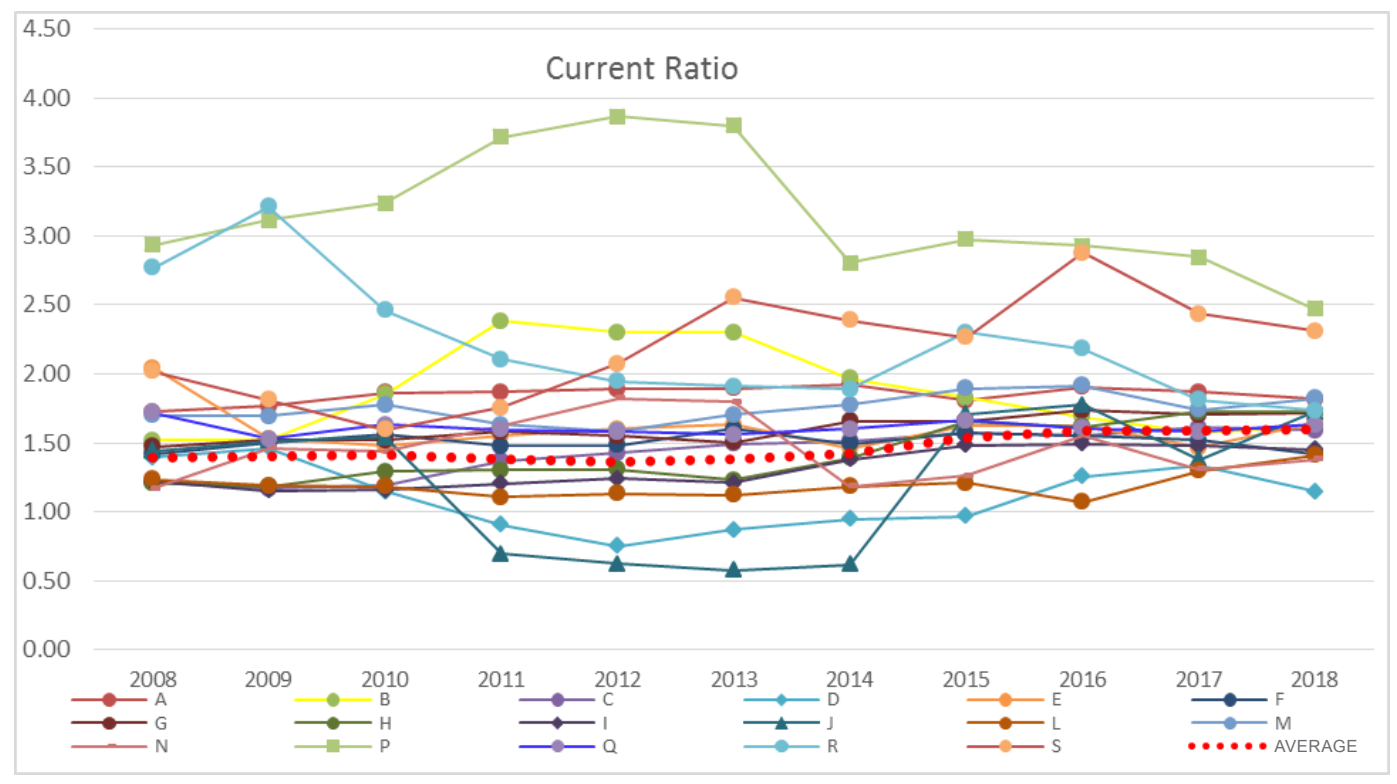

Figure 1. Current Ratio of NFC Sectors

Source: NSI, own Analysis

The current liquidity ratio by individual economic sectors shows various values and dynamic changes. It is noteworthy that these values, based on the 11-year study period, are in a wide range - between 0.57 for sector J. Creation and dissemination of information and creative products; telecommunications in 2013 and 3.87 for sector P. Education in 2014. At the beginning of the period the highest values are in sector $P$ and sector $R$. At the end of the period $R$ is replaced by sector $\mathrm{S}$. On the other hand, the lowest values are registered for sectors J, D, L. The average current indebtedness based on all sectors for the whole period ranges between 1.39 in 2008 and 1.60 in 2018. The lowest average is 1.36 in 2012, while the highest is in 2018. The benefits of this average line of the current liquidity ratio are associated with the ability to determine which sectors are below it, i.e., have lower liquidity and which have higher. Sectors $\mathrm{C}, \mathrm{H}, \mathrm{I}, \mathrm{L}, \mathrm{N}$ are below the average current liquidity throughout the study period. They have liquidity problems. Such dependence can only be established through a survey of enterprises in these sectors. The sectors that in one part of the period have lower than the average current liquidity, and in another have higher are: D, F. All other sectors have higher than the average current liquidity for the respective years. These are $A, B, E, G, J, M, P, Q, R, S$. On this basis, they can be interpreted as sectors with riskier indicators of current liquidity than others, but this does not mean for sure that they have liquidity problems. Such dependence can only be established through a survey of enterprises in these sectors. The average current liquidity in all years is $\mathbf{1 . 4 6 .}$

Figure 2 shows the state of the quick liquidity ratio, which is a more severe test of the solvency of the company, because the lowest liquid current assets are eliminated, namely inventories. Enterprises in the manufacturing and trade sectors tend to have higher inventories than those in the 


\section{Articles}

services sector. The highest values are in the sectors G. Trade, C. Manufacturing and F. Construction. They should also have the highest differences between current and quick liquidity. For example, in 2018, sector G. covers $172 \%$ of the short-term debt at the expense of all current assets, and eliminating inventories covers $106 \%$. In sector $\mathrm{C}$ the levels for the same year are respectively $159 \%$ vs $91 \%$ coverage of short-term liabilities. In other sectors the difference between the two indicators is insignificant due to the low levels of inventories, for example sector R. - $247 \%$ vs $239 \%$. The figure below shows that the highest levels of quick liquidity are in sectors $\mathrm{P}, \mathrm{R}, \mathrm{S}$, and the lowest are in $\mathrm{J}, \mathrm{D}, \mathrm{C}$.

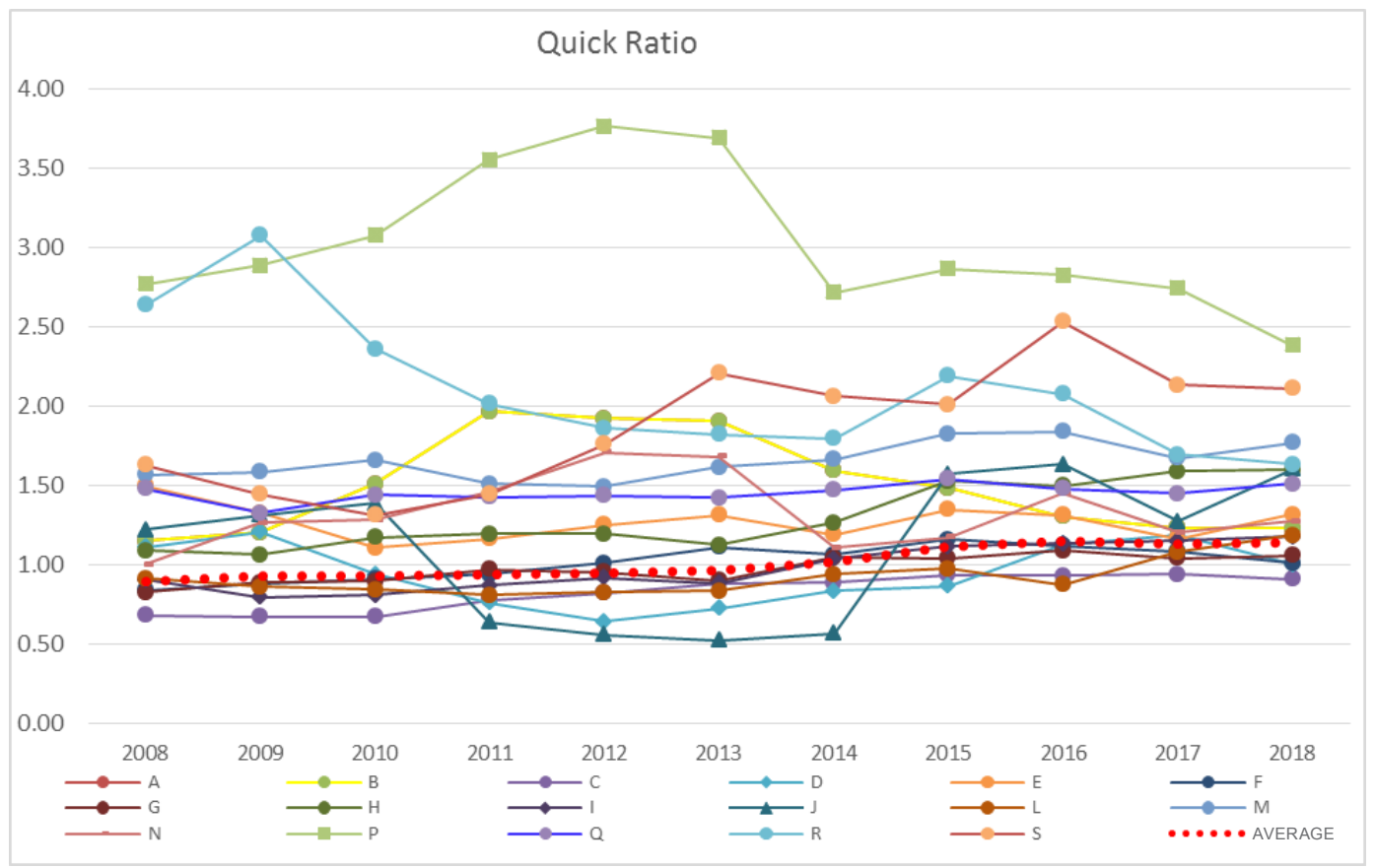

Figure 2. Quick Ratio of NFC Sectors

Source: NSI, own Analysis

Expert statements on the recommended levels of quick liquidity are contradictory, but for the most part defend the thesis that the normal limits of the ratio are in the range of 0.7 to 1 . These conclusions are based on the analysis of individual companies. There is no such analysis in Bulgaria, which unites all non-financial enterprises, for 2018 the sample includes 340,829 enterprises. The ratios, as well as those for liquidity, are particularly appropriate because they give results regardless of the number of companies, as opposed to absolute indicators. It turns out that the thesis of the recommended levels is proved to some extent, because most sectors maintain an average quick liquidity around and slightly above 1 . Only sectors D, G, I, J, L have lower values than the average, but this is not at all for the whole period. The weakest quick liquidity was registered by sector $\mathrm{J}$ in $2012-0.56$, while the highest sector $R$. registered 3.77 in the same year. Interestingly, the current liquidity in 2012 for sector $\mathrm{J}$ was 0.57 , almost equal to the quick one, which 


\section{Articles}

means that the levels of inventories are low. It is noteworthy that over the years the average quick liquidity measured on the basis of data for all enterprises increased from 0.90 in 2008 to 1.14 in 2018. This means an improvement in terms of solvency and providing a higher amount of the asset to repay the short-term debt. The average quick liquidity on an allyear basis is 1.02 . This means that even
Liquidity of Non-financial Corporations: Evidence from Bulgaria

without relying on inventories, non-financial corporations cover their short-term liabilities.

Figure 3 shows the cash liquidity ratio, which is the most severe test of the company's solvency. It relates cash on accounts to and in cash to short-term liabilities. This indicator gives an idea of how much of the short-term debt can be repaid immediately, because cash can be committed immediately to repaying it, unlike other less liquid current assets.

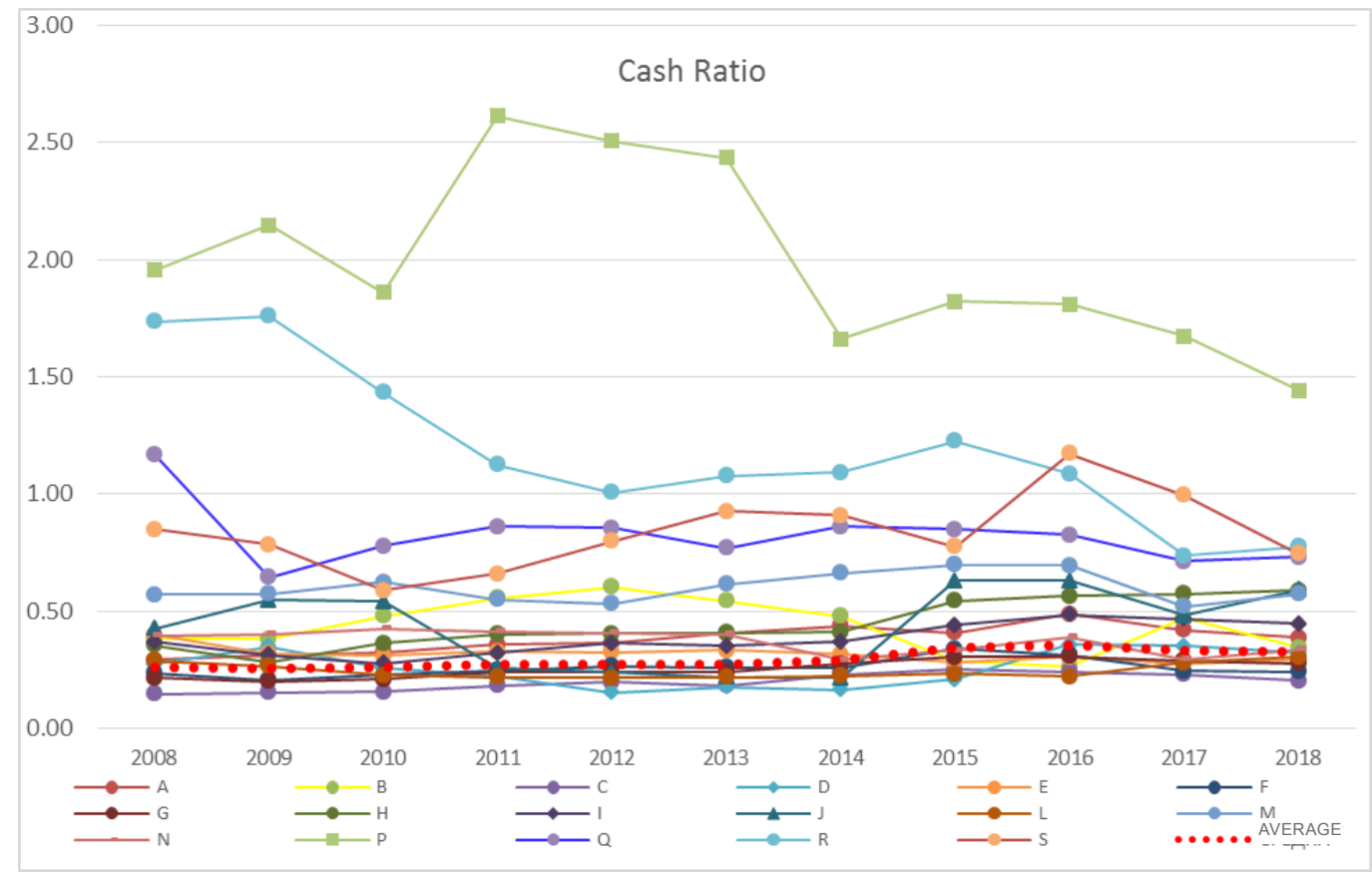

Figure 3. Cash Ratio of NFC Sectors

Source: NSI, own Analysis

It is clear from the figure that the leaders in the highest cash liquidity are sectors $P$ and $R$. The values in sectors $Q$ and $S$ are also high. The levels of the indicator for these four sectors are high and well above the accepted norms of practice and experts. Excessive cash liquidity means that money freezes in the form of an asset and does not bring additional income, instead of investing and providing a return. Below the middle line in 2018 are sectors C, F, G, D, E, while in 2008 were only the first three of these. All other sectors have values above the average, which in 2008 were 0.26, and in $2018-0.33$. There is an increase in the average values of all coefficients for this 11-year period. According to most experts, the ratio should be between 10 and $30 \%$ debt coverage, but 


\section{Articles}

in our opinion these recommended values cannot be protected because they are strictly individual for each company, but also for each sector, which is clearly visible on the figures above. In this regard, the lowest reported value is in sectors $C$ and $D$ in the initial years of the survey -0.15 , and the highest in sector
$P-2.61$ in 2011. This is a serious range, which proves the industry conditionality.

Table 1 discusses the average values of structural liquidity ratios by sectors, separated by the so-called average of two groups, sectors with values below and sectors with values above the average.

Table 1. Sectoral average values of structural liquidity ratios based on an 11-year period.

\begin{tabular}{|c|c|c|c|c|c|}
\hline Sector & $\begin{array}{c}\text { Current } \\
\text { Ratio }\end{array}$ & Sector & $\begin{array}{l}\text { Quick } \\
\text { Ratio }\end{array}$ & Sector & $\begin{array}{l}\text { Cash } \\
\text { Ratio }\end{array}$ \\
\hline$J$ & 1,04 & C & 0,83 & C & 0,20 \\
\hline D & 1,05 & D & 0,90 & D & 0,24 \\
\hline L & 1,19 & L & 0,92 & L & 0,24 \\
\hline I & 1,32 & $J$ & 0,95 & $\mathbf{F}$ & 0,25 \\
\hline C & 1,43 & G & 0,98 & G & 0,26 \\
\hline H & 1,44 & I & 0,99 & AVERAGE & 0,30 \\
\hline N & 1,44 & $F$ & 1,00 & E & 0,31 \\
\hline AVERAGE & 1,46 & A & 1,02 & N & 0,36 \\
\hline$F$ & 1,51 & AVERAGE & 1,02 & $J$ & 0,37 \\
\hline$E$ & 1,59 & $E$ & 1,26 & I & 0,38 \\
\hline G & 1,61 & H & 1,32 & A & 0,39 \\
\hline $\mathbf{Q}$ & 1,61 & N & 1,32 & B & 0,43 \\
\hline M & 1,75 & Q & 1,46 & H & 0,45 \\
\hline B & 1,84 & B & 1,47 & M & 0,60 \\
\hline A & 1,85 & M & 1,66 & $\mathbf{Q}$ & 0,81 \\
\hline $\mathbf{R}$ & 2,12 & $S$ & 1,92 & $S$ & 0,83 \\
\hline$S$ & 2,22 & $\mathbf{R}$ & 2,01 & $\mathbf{R}$ & 1,11 \\
\hline $\mathbf{P}$ & 3,07 & $\mathbf{P}$ & 2,96 & $\mathbf{P}$ & 1,91 \\
\hline
\end{tabular}

Source: NSI, own Analysis

The table shows that the lowest average current liquidity ratio is sector $\mathrm{J}-1.04$. A good sign is that the values are still above 1 . Sector D follows, with 1.05. Below the middle line are also sectors $L, I, C, H, N$. Sector $P$ registers the highest value of the indicator. In fact, only in sectors $P$ and $D$ and the four average coefficients are at the respective positions, 


\section{Articles}

without any change. Sectors F, E, G, Q, M, B, $A, R, S$ are also above the average current liquidity.

With the quick liquidity, it turns out that there is a shift in the sectors. The lowest value is sector $\mathrm{C}-0.83$, which is not a problem for the sector because it is in line with the recommended levels. Sectors D, L, J, G, I, F, A follow the average value, and above 1.02 are the other sectors $E, H, N, Q, B, M, R, S$, $P$. Again, sector $P$ is with the highest value 2.96. For example, sectors $F$ and $A$ are with current liquidity above average and with quick liquidity below. This is a very important point, illustrating how different the three structural liquidity ratios are and what different types of information they provide us.

The difference between the average quick and the average cash liquidity is noticeable from 1.02 to 0.30 . This shows that the most significant share of current assets is occupied by inventories and receivables. However, it turns out that the levels of receivables are significantly higher. The total inventories of all sectors for the whole period are 443 billion leva, while the receivables are 691 billion leva. The static nature of the preparation of the financial statements must also be considered. Below the average value of immediate liquidity are sectors C, D, G, L, F, E, and above it the others. The highest values are registered at $P$ - 1.97 and at $R$ - 1.15. The difference between the two most liquid sectors in this indicator is also noticeable. Sector $P$ stands out as a phenomenon in terms of high structural liquidity indicators.

Cash liquidity averages are between 0.20 for sector $C$ and 1.91 for sector $P$. This
Liquidity of Non-financial Corporations: Evidence from Bulgaria

difference is significant and again proves sector conditionality. Below the line of 0.30 , which is the average value for absolute liquidity, are also sectors D, L, F, G. Although below this line, all five sectors show very good coverage of short-term debt at the expense of cash - from over $20 \%$. All other sectors have higher than average values. Sectors $Q, R$, S, P show excessively high levels, over $80 \%$ coverage. Due to the inverse proportionality of liquidity and profitability, high levels of cash liquidity led to loss of income.

\subsection{Cash Conversation Cycle (Hristozov, 2021)}

The Cash Conversion Cycle is a metric that expresses the time (measured in days) required for an enterprise to convert its investment in inventories and other resources into cash flows from sales. Also called a net operating cycle, or simply a cash cycle, the cycle tries to measure how long each net incoming lev is tied up in the production and sales process before being converted into cash received. In Bulgarian literature it is also found as a production cycle or financial cycle. The cash conversion cycle was introduced by Richards and Laughlin (1980), who proposed it as a dynamic indicator in liquidity analysis. The three components of the cash conversion cycle (CCC) (https://fundbox.com/blog/cashconversion-cycle/) are:

- Days Inventory Outstanding (DIO) - the average time to convert the inventory into finished goods and then sell them.

- Days Sales Outstanding (DSO) - the average number of days your accounts receivable take to be collected. 
Articles

- Days Payable Outstanding (DPO). - the average length of time it takes the firm to purchase from vendors and then pay (the accounts payable) them.

CCC $=$ Days Inventory Outstanding (DIO)

+ Days Sales Outstanding (DSO) - Days Payable Outstanding (DPO)

While the cash conversion cycle is usually a positive figure, some companies may have a negative cash conversion cycle. In this situation, the company effectively receives payments for the goods it sells before paying its suppliers for materials (https://taulia.com/ glossary/what-is-the-cash-conversion-cycle$\mathrm{ccc} /$ ).

Katerina Lyroudi and Yiannis Lazaridis (2000) have analyzed the cash conversion cycle as a liquidity indicator of the food industry in Greece and have tried to determine its relationship with the current and the quick ratios, with its component variables, and investigated the implications of the cash conversion cycle in terms of profitability, indebtedness and firm size. The results indicate that there is a significant positive relationship between the cash conversion cycle and the traditional liquidity measures of current and quick ratios.

Any change in the length of the financial cycle changes the conditions of the financial equilibrium of the enterprise and the amount of money needed to carry out the cycle. Extending the financial cycle means freezing money in the form of real assets or receivables. Starting a new cycle will require extra money and pose a potential solvency problem. On the other hand, accelerating the financial cycle will free up money and make it possible to increase the scale of the cycle or to reduce the need for net working capital. The duration of the financial cycle has its objective roots in technology, market, etc. the conditioned duration of the production cycle of the enterprise.

Figure 4 clearly shows the duration of the sectors in days. This indicator is the longest in sector L. Real estate activities. Sectors A, S, $F$ follow. In these sectors the production cycle is the riskiest from the point of view of liquidity because it takes the longest time for the traded products / services to turn into money. The best levels of the indicator are in sectors J, D, Q, I. In these sectors the values are even negative, which indicates a high turnover of inventories, receivables and liabilities.

In terms of dynamics, the most significant changes are observed in sector $L$ in the period 2011-2014, these are the years after the crisis, in which the levels are particularly high, which indicates a worsening of the situation. Another similar sharp change is observed in sector $\mathrm{J}$, but in a positive direction. In the period 20212015, the duration of the cycle decreases dramatically, which draws our attention in the figure. The dashed line on figure 4 shows the average value of this indicator, measured on the basis of all sectors and the whole period. The average ranges from 15 days in 2008 to 30 days in 2018. This means a double extension of the research sector to an 11-year period, which is an argument in favor of deteriorating liquidity and confronting companies with higher risks of insolvency. 


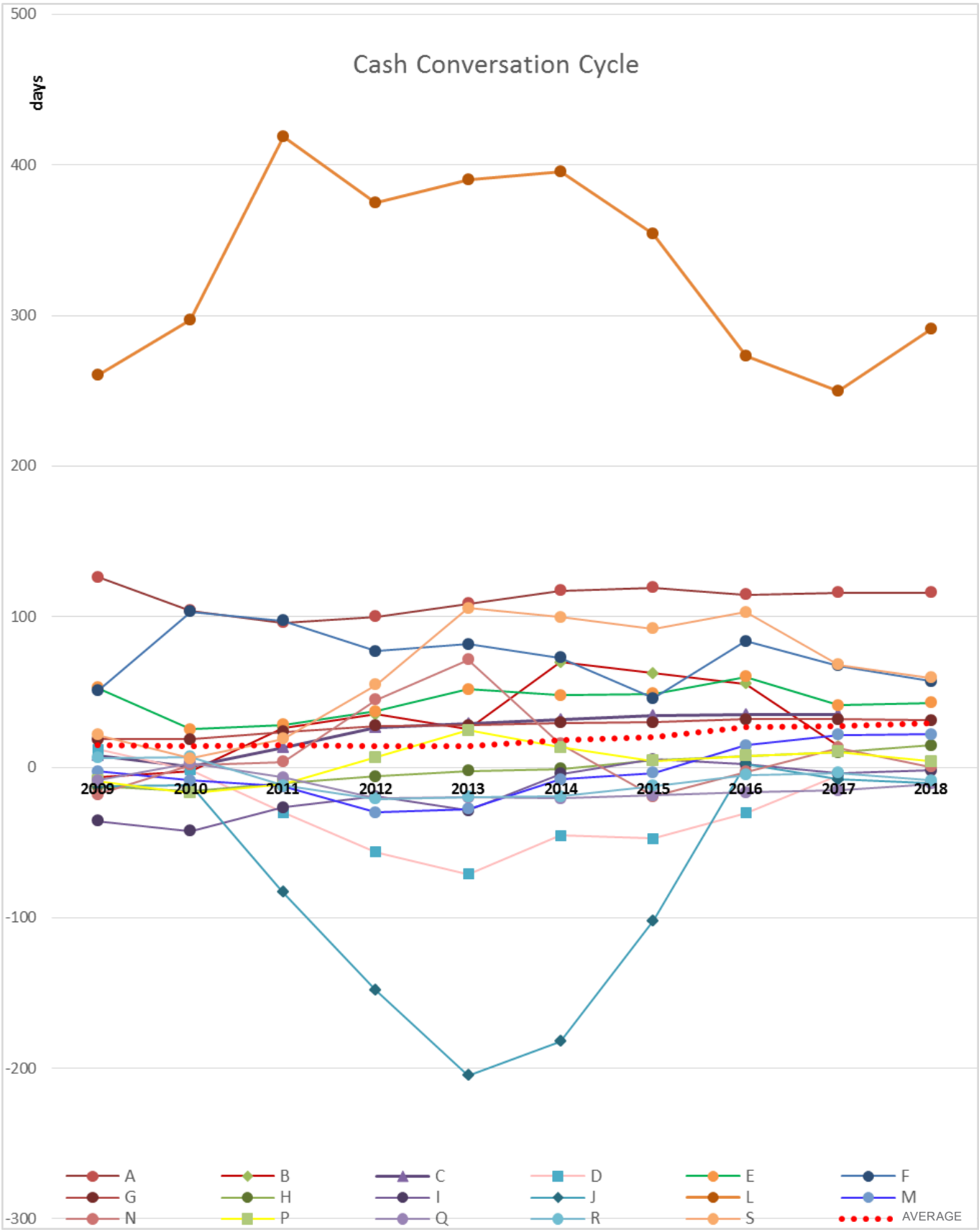

Figure 4. Cash conversation Cycle by Sectors

Source: NSI, own Analysis 


\section{Articles}

To illustrate more clearly the sectoral conditionality and the significant difference in the length of the financial cycle in the individual sectors, the following table is presented, which shows the average values by sectors based on the whole period

Table 2. Average sectoral Duration of the Cash conversation Cycle by Sectors

\begin{tabular}{|c|c|}
\hline SECTOR & $\begin{array}{c}\text { CASH CONVERSATION CYCLE } \\
\text { (days) }\end{array}$ \\
\hline J & $-68,35$ \\
\hline D & $-27,70$ \\
\hline Q & $-14,22$ \\
\hline I & $-13,86$ \\
\hline R & $-10,72$ \\
\hline M & $-0,69$ \\
\hline H & 0,70 \\
\hline P & 3,86 \\
\hline N & 7,10 \\
\hline AVERAGE & $\mathbf{2 0 , 5 8}$ \\
\hline B & 26,62 \\
\hline G & 27,74 \\
\hline C & 27,76 \\
\hline E & 43,61 \\
\hline F & 67,62 \\
\hline S & 71,65 \\
\hline A & 115,58 \\
\hline L & 328,91 \\
\hline & (n) \\
\hline
\end{tabular}

Source: NSI, own Analysis

The sectors below and above the average are almost the same number. A more significant risk may exist in sectors $F, S, A$, $\mathrm{L}$, which have an average cash conversation cycle length of more than 60 days. This risk is lowest in the below-average sectors because they all have a very short cycle, even a negative one. This is because the turnover of liabilities is higher than that of receivables and inventories combined. In general, according to the data in the table, it cannot be said with certainty that, for example, liquidity problems are necessarily observed in sector L., but the table provides us with clear evidence of sectoral conditionality. The average duration is just over 20 days. The management and control of a company's liquidity can include several indicators and approaches, for example: identification of key variables in the financial statements, tracking changes in the need for liquidity; maintaining a stock of highly liquid assets and constant access to a variety of market-based financing instruments; contingency planning. The indicators that could alert the management to possible liquidity problems or problems related to excessive indebtedness come mainly from the factors that affect these financial indicators. Liquidity management is part of financial planning and serves to maintain the solvency of the enterprise. The financial and liquidity plans are set as short-term, medium-term and longterm plans in accordance with the objectives. From today's point of view, long-term planning can be calculated very inaccurately, so the burden lies on short-term and medium-term planning. Annual liquidity plans must be drawn up and changed quarterly or monthly. In this way, solvency can be ensured in a timely manner and managed with less cash. Due to the known and expected business processes, for example, the security of the respective liquidity needs can be determined through an annual plan (Ossola-Haring, C, 2006).

In distinguishing between indicators, a distinction must be made between inflows and outflows. Cash outflows relate to the enterprise's current fixed costs, personnel costs and costs of purchasing goods and external services. Other public obligations and taxes must also be considered. Cash inflows arise essentially through the sale of 


\section{Articles}

goods and services, through the sale of rights and assets, and through tax refunds. Liquidity includes the following funds: Cash available; Daily maturities of bank loans; Available credit lines. These liquidity tools are of the first degree when it comes to ensuring relatively fast availability. The liquidity of the second and third degree includes the funds, the availability of which is possible only in case of time delay. These are: Cash and short-term receivables; Current assets or inventories (Uhlig, S., 2000).

Liquidity is affected by several influencing factors that need to be taken seriously during the planning of this indicator and the development of warning indicators and management approaches. They can not only improve the two key indicators, but also significantly reduce the financial risk. The relationship between factors, indicators and liquidity is as follows:

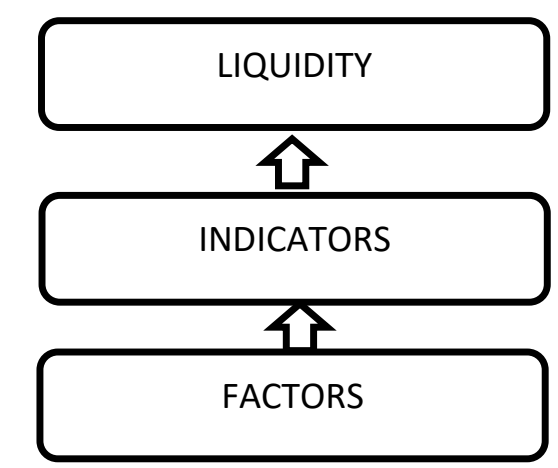

Figure 5. Dependencies of liquidity and indebtedness indicators

Source: own Analysis

The main factors influencing liquidity can be considered as integral parts of their measurement methods. From the point of view of liquidity, the current study examined the structural liquidity and cash conversation cycle. In this regard, the management of these factors is related to the management of assets and liabilities in the enterprise, as well
Liquidity of Non-financial Corporations: Evidence from Bulgaria

as net sales revenue, operating expenses and the realization of current profits or losses.

\section{Early warning indicators for liquidity problems}

\subsection{Indicators in terms of short-term liquidity}

Before commenting on the management and use of assets as an indicator, the following dependencies should be considered, which should not be violated, namely: the expected value of current assets is formed by the long-term optimal value of net working capital and the minimum possible value of current liabilities. In the conditions of growth, this model makes it possible to apply an aggressive strategy with lower liquidity and a higher potential for increasing turnover and profitability (Raykov, E, 2017).

The maturity of corporate debt should not be ignored because it is essential to clarify and is of interest to corporate finance. This issue has become particularly relevant after the financial crises and shows a significant mismatch between asset maturity and debt maturity. More importantly, it turns out that companies are willing to finance fixed assets with short-term debt, thus violating the golden balance of equity to finance fixed assets entirely with long-term debt (Adachi-Sato, M., Vithessonthi, Ch., 2019)

In connection with the factors that affect the structural liquidity in terms of assets, indicators can be identified that signal emerging risks or problems for enterprises. The factors based on the coefficients used are the following: amount of current assets, incl. inventories, receivables, investments, cash, amount of short-term liabilities. A change in any of these positions may lead to a deterioration in short-term liquidity or 


\section{Articles}

indebtedness. Their general interpretation: lower values indicate lower ability to repay short-term liabilities, too high values can mean inefficiency - it is advisable to evaluate together with turnover ratios, ideal values should be neither low nor high recommended ideal values within the description of each indicator separately.

However, when comparing the obtained values with the recommended values, some distortions are possible depending on the sector of activity, the type of enterprise, etc. Therefore, it is important to compare the indicators in time series. If the company does not meet the recommended values, but copes with the financial challenges without problems, then it can be expected that it will continue to be successful with the same values in the future. Therefore, in the current study, the main priority is the derivation of average values by industry and as a whole economy, which companies can use as a reliable indicator and benchmark.

Problems with short-term liquidity usually arise in two directions: too high values or, conversely, too low values. In this regard, decisions are made by the financial management to influence the ratios. In case of low / high liquidity and willingness to monitor the influencing factors and indicators, attention should be paid to:

- increase / decrease in the amount of inventories

- increase / decrease in the amount of current receivables

- increase / decrease in the amount of current investments

- increase / decrease in the amount of cash

- increase / decrease in the amount of short-term receivables
Significant changes in the values of the above factors are an indicator of change that must be traced historically and forecast in the future to identify possible risk conditions for a particular enterprise.

\subsection{Indicators from the point of view of the financial cycle}

The cash conversion cycle (Financial cycle) is one of the indicators of activity and liquidity, which shows the number of days starting from the date of payment for purchased materials, labor and other costs to collect cash for receivables. Decisions for managing the financial cycle are made on the basis of the goal of its reduction, i.e., the shortening of the period from the payment of the raw materials to the moment of receiving the payment for the sale. The factors that affect the financial cycle are the period of turnover of inventories, receivables and payables. The following changes will be a sign of deterioration of the indicator and if this is excessive, it would affect the liquidity of the company:

The significant decrease in the period of turnover of inventories (i.e., increase in the days of turnover of inventories) is an indicator of deterioration in terms of liquidity and may be due to increased levels of inventories and / or a significant decline in net sales revenue. This will result in fewer turnovers that carry inventory within a year to turn into money. This increase may be due to poorer sales results or due to stagnation of goods, or the desire to maintain higher levels to achieve higher sales, based on the function - turnover is a function of availability. Reducing the value of inventories can be done by reducing their average level and by optimizing supplies.

Significant reduction of the period of turnover of receivables (i.e., increase of the 


\section{Articles}

days of turnover of short-term receivables) is an indicator of deterioration in terms of liquidity, which may be due to outstanding and overdue payments to the company by customers. There are various approaches that the company can take to increase the collection of receivables and negotiate shorter periods of deferred payment to customers. The increase in the period of turnover of receivables may also be due to a significant decrease in net sales revenue. The approaches for their increase are also clear, but rather in theory, and the effects of their application in practice do not always bring the desired results.

A significant increase in the period of turnover of liabilities (i.e., reduction of the days of turnover of liabilities) is an indicator of deterioration in terms of liquidity. The possibilities for the impact of this indicator are by increasing the liabilities, which can be achieved by negotiating or overdue repayment of the debt, when this does not lead to risks of lawsuits or payment of penalty interest and fees. These are short-term liabilities to suppliers, tax, social and social security payments, liabilities to staff, etc.

\section{Conclusion}

The study on corporate liquidity is relevant, interesting and significant for financial theory and practice, and potential users of this information are mostly non-financial companies. The main problem that provoked the research was that there are no analyses of the liquidity status of enterprises in Bulgaria.

The results obtained show that these liquidities have a strict sectoral (sectoral) conditionality. There were significant differences in liquidity, measured by two methods. For example, when applying a structural liquidity analysis, the indicators are the lowest in sectors J, C, D, while the highest
Liquidity of Non-financial Corporations: Evidence from

Bulgaria

are in sectors $\mathrm{P}, \mathrm{S}, \mathrm{R}$. In the financial cycle, the longest period of turnover is observed in sectors $L, A, S$, and the shortest in sectors $J, D, Q$. The question is not so much what the levels of liquidity are, but how to find the optimal level that satisfies the solvency of an enterprise.

But it has been unequivocally shown that liquidity should not be judged by just one of the methods of analysis and evaluation listed. The research hypothesis that it is possible to build a methodology for ongoing assessment of the status of this indicator at the national level and to prove sectoral conditionality and on this basis to propose early warning indicators to assist management in dealing with insolvency risks and liquidity problems, is evidenced by numerous facts and arguments.

By solving the set research tasks the main aim of the research is achieved, namely, to study the liquidity status of enterprises in the non-financial sector in Bulgaria, to derive early warning indicators for problems related to solvency. It was essential to derive industrywide values of liquidity ratios to serve as a benchmark for maintaining the necessary levels of liquidity in the respective sectors.

The author plans to look for the interrelationship between liquidity and profitability in the future, as well as to consider the impact of indebtedness on these two indicators. This will make it possible to analyze the extent to which the inverse proportionality of liquidity affects profitability. It will be especially interesting to analyze the impact of the CoVid-19 crisis on key financial indicators of Bulgarian enterprises, while looking for analogues for comparison with other European countries, when statistical information for the respective years is available. After studying several sources, the latter is also an extremely difficult task, as 


\section{Articles}

there are no ready-made studies of these indicators at the level of sectors and nonfinancial corporations in other countries Bulgaria.

*This article contains results of a study funded by a targeted subsidy of the University of National and World Economy under contract NID NI-4/2018, led by Yanko Hristozov.

\section{References}

Adachi-Sato, M. \& Vithessonthi, Ch. 2019. "Corporate debt maturity and future firm performance volatility," International Review of Economics \& Finance, Elsevier, vol. 60(C), pages 216-237.

Allen, Franklin and Carletti, Elena, The Role of Liquidity in Financial Crises (September 4, 2008). Available at SSRN: https://ssrn.com/ abstract $=1268367$

Breitkreuz, G. 2007. Ohne Liquidität keine Überlebenschance, Tecum Verlag, Marburg, 2007

Chobanov, P., Nenovsky, N. 2004. "Money market liquidity under Currency board empirical investigations for Bulgaria," PostPrint halshs-00259753, HAL.

Emery, Gary W. 1987. An Optimal Financial Response to Variable Demand, Journal of Financial and Quantitative Analysis, Vol.22, No. 2

Erichsen, T. 2016. Professionelles Liquiditätsmanagement, 2 Auflage, NWB Verlag, Herne, Germany

Heesen, B. 2016.Cash- und Liqiditätsmanagement, 3 Auflage, Springer Gabler, Wiesbaden, Germany

Holden, Craig W. and Jacobsen, Stacey E. and Subrahmanyam, Avanidhar, The Empirical Analysis of Liquidity (October 2, 2014). Foundations and Trends in Finance 8, No 4, 263-365, 2015, Kelley School of Business Research Paper No. 2014-09, Available at SSRN: https://ssrn.com/abstract=2402215 or http:// dx.doi.org/10.2139/ssrn.2402215

Homonnof, T., Spreen Th., Clair, T. 2020. Balance sheet insolvency and contribution revenue in public charities. Journal of Public Economics, 186, 104177, https://doi. org/10.1016/j.jpubeco.2020.104177

Hotchkiss, E., \& Mooradian, R. 1998. Acquisitions as a means of restructuring firms in chapter 11. Journal of Financial Intermediation, 7, 240-262

Lyroudi, Katerina and Lazaridis, Yiannis, The Cash Conversion Cycle and Liquidity Analysis of the Food Industry in Greece (June 2000). Available at SSRN: https://ssrn.com/ abstract $=236175$

Maksimovic, V., \& Phillips, G. (1998). Asset efficiency and reallocation decisions of bankrupt firms. Journal of Finance, 53, 14951532

Michalski, Grzegorz, Liquidity or Profitability: Financial Effectivness of Investments in Working Capital (June 25, 2008). INTERNATIONAL FINANCIAL SYSTEMS, P. Cervinek, ed., BRNO, 2008, Available at SSRN: https://ssrn.com/abstract $=1299586$

National Statistics Institute, www.nsi.bg

Nenkov, D., Hristozov, Y. 2020. Corporate Finance. Textbook. UNWE, Sofia (in Bulgarian) Nenkova, P., Popova, N., Metalova, D. 2021. Public Finances on the Balkan Peninsula - A Comparative Study of Twelve Countries, Finance, Accounting and Business Analysis, 3 (1), Public Finance Institute, 12-30

Nikolova, N. 2010. Principles of Corporate Finance, Ciela, Sofia (in Bulgarian)

Ossola - Haring, C., 2006. Die besten 150 Checklisten zur Liquiditätssicherung, Fachverlag, Landsberg am Lech

Panigrahi, Ashok, Relationship of Working Capital with Liquidity, Profitability and Solvency: A Case Study of ACC Limited 


\section{Articles}

(January 16, 2014). Asian Journal of Management Research, Volume 4 Issue 2, 2014, Pp 308-322, Available at SSRN: https:// ssrn.com/abstract $=2379986$

Ortiz-Molina, H., \& Phillips, G. (2014). Real asset illiquidity and the cost of capital. Journal of Financial and Quantitative Analysis, 49, pages 1-32

Pham, Ly Thi Minh \& Vo, Lai Van \& Le, Huong Thi Thu \& Le, Danh Vinh, 2018. "Asset liquidity and firm innovation," International Review of Financial Analysis, Elsevier, vol. 58(C), pages 225-234.

Raykov, E. 2017. Integrated approach to working capital management in the financial and economic crisis, UNWE, Sofia (in Bulgarian) .

Raykov, E. 2017. The liquidity-profitability trade-off in Bulgaria in terms of the changed financial management functions during crisis, Journal of Contemporary Management Issues, Vol. 22 (1), pages 135-155

Schlingemann, F., Stulz, R., \& Walkling, R. (2002). Divestitures and the liquidity of the
Liquidity of Non-financial Corporations: Evidence from Bulgaria

market for corporate assets. Journal of Financial Economics, 64, pages 117-144

Shleifer, A., \& Vishny, R. 1992. Liquidation values and debt capacity: A market equilibrium approach. Journal of Finance, 47, pages 1343-1366

Stahl. Weber-H. 2018. Finanz- und Liquiditätsplanung. Taschen Guide, 4. Auflage, Haufe, Freiburg, Germany

Tobias, A., Hyun Song S., Liquidity and Leverage (January 1, 2009). FRB of New York Staff Report No. 328, Available at SSRN: https://ssrn.com/abstract $=1139857$

Uhlig S. 2000. Immer zahlungsfähig, Printul Verlag

Widyastuti, M. 2019. Analysis of Liquidity, Activity, Leverage, Financial Performance and Company Value in Food and Beverage Companies Listed on the Indonesia Stock Exchange, International Journal of Economics and Management Studies 6 (5), pages 52-58 https://fundbox.com/blog/cash-conversioncycle/

https://taulia.com/glossary/what-is-the-cashconversion-cycle-ccc/ 